\title{
Cartas ao editor
}

\section{Letters to the editor}

"Nós somos tecidos com o mesmo tecido com que se tecem os sonhos; nossas curtas vidas são cercadas de sonhos."

William Shakespeare, A tempestade

Queridos amigos:

Quis a generosidade da diretoria da Sociedade Brasileira de Medicina de Família e Comunidade (SBMFC) agraciar-me dando o meu nome a um dos Prêmios na Premiação de Trabalhos Científicos no $9^{\circ}$ Congresso Brasileiro e no $2^{\circ}$ Congresso Cearense de Medicina de Família e Comunidade, que ocorreram em Fortaleza/CE, em maio deste ano, junto ao $1^{\circ}$ Simpósio Internacional de Educação em Medicina de Família e Comunidade e Atenção Primária à Saúde.

Essa honra eu agradeço a SBMFC, por meio de sua diretoria, sensibilizado e comovido, pois se tornou um reconhecimento público e um resgate histórico de minha contribuição para o desenvolvimento da saúde no país com a criação do primeiro sistema comunitário de saúde instalado no Brasil.

Agradeço também a todos que de diversas formas, externaram seu carinho muito especial e expressaram seus cumprimentos a minha pessoa, o que honrou de tal maneira que me senti tão premiado quanto aos colegas Médicos de Família e Comunidade cujos trabalhos científicos foram premiados no Congresso. Associaram, assim, a minha pessoa aos nomes de colegas ilustres no campo da Medicina de Família e Comunidade, tais como Bárbara Starfield, Carlos Grossman, Hafdan Mahler, Ricardo Donatto, Dante Romano e Kurt Kloetzel. O fato em si e os cumprimentos que se seguiram exigem de minha parte um agradecimento, e eu o faço honrado.

Pensei também que caberia, neste meu agradecimento, dizer algo sobre dados históricos e também sobre o significado do trabalho desenvolvido por um grupo excepcional de colegas e por mim, entre os anos 1972 e 1982, para a criação de um modelo escalonar hierárquico de um Sistema de Saúde Comunitária. Faço esse resgate agora como um dever também pelo privilégio de ter tido, no referido trabalho, uma atuação destacada. Tudo ocorreu no Centro Médico Social São José do Murialdo (CMSSJ), localizado à Rua Vidal de Negreiros, 443, um grande Centro de Saúde da então Secretaria de Saúde e do Meio Ambiente, que abrigava um programa de estágio de alunos da Faculdade de Medicina da Universidade Federal do Rio Grande do Sul (FAMED - UFRGS), programa esse que o seu coordenador à época, Dr. Nelson Macedo de Resende, batizou com o nome de Estágio de Medicina Integral.

O Dr. Nelson era um idealista dentro do ensino convencional, que vindo do lendário Serviço de Saúde Pública

*Médico, mestre em saúde pública e saúde mental, assessor especial da UFRGS.

084 Rev Bras Med Fam e Com

Rio de Janeiro, $v 4$, no 14 , jul /set 2008 
do Ministério da Saúde, o famoso SESP, lecionava no Departamento de Medicina Preventiva da FAMED UFRGS. Ao referir o trabalho do Dr. Nelson, sinto-me resgatando a sua atuação no desenvolvimento do que era então uma inovação pedagógica, mas que, com as contribuições que foi recebendo dos que para lá se deslocaram, tornar-se-ía o embrião de algo maior. Levar alunos do curso de graduação em medicina a conhecerem a comunidade real, em local que compreendia diversos conglomerados, onde se localizavam os domicílios dos usuários dos serviços de saúde e de suas famílias, cujo nível sócio-econômico se estendia de classe média até os de pobreza extrema, era do ponto de vista tanto pedagógico como de exposição de alunos à realidade médico-social, algo inédito por seu caráter formativo, e tinha por objetivo possibilitar mudanças de atitudes nos alunos do curso de graduação em medicina da UFRGS.

Ao grupo que atuava no CMSSJ do Murialdo, fui me associar já na década de 1960, mais precisamente em 1966, com idéia de integrar, ao que lá se fazia em termos de Saúde Pública, o componente Saúde Mental. Foi o meu interesse em Psiquiatria Comunitária e Social que me levou a desenvolver atividades de Saúde Mental integradas as de Saúde Pública. Penso ter sido esta a origem das demais atividades que tornaram aquela área um campo de experiências em Extensão de Cuidados de Saúde Física, Mental e Social, o qual tive o privilégio de liderar.

Posteriormente, o CMSSJ do Murialdo recebeu a denominação de Unidade Sanitária Murialdo. Naquele local fomos descobertos, percebidos, reconhecidos, adotados e registrados pela Organização Mundial de Saúde (OMS) e pela Organização Pan-Americana da Saúde (OPAS). A partir daí, veio o reconhecimento do mundo científico, que passou a ver a Unidade Sanitária Murialdo como um local dentro da comunidade onde se desenvolviam pela primeira vez em nosso país atividades experimentais e inovadoras de assistência, ensino, pesquisa e administração em Saúde Pública, de extrema importância. A OMS e a OPAS prestigiaram a nós e aos colegas que conosco trabalhavam, Bruno Russomano de Mendonça Lima e José Manoel Bertolote, tornando-nos seus colaboradores, na qualidade de assessores temporários e membros de seus painéis de peritos. A Secretaria da Saúde e sua Escola de Saúde Pública, dada a importância que a Unidade Sanitária Murialdo adquiriu em assistência, ensino, pesquisa e administração para a Saúde Pública no Rio Grande do Sul, veio a assumi-la e mantê-la como estadual, e a denominaram com o seu atual nome de Unidade Sanitária Escola Murialdo.

Após um período de familiarização com a Saúde Mental Comunitária, nos últimos anos da década de 1960, já psiquiatra, psicanalista e Professor no Departamento de Psiquiatria e Medicina Legal da UFRGS, fui me obrigando a usar meus conhecimentos dentro da Saúde Pública, e aceitei um desafio da OPAS para ampliar meus estudos em Saúde Mental dentro da perspectiva da Saúde Pública. Fui levado a um mestrado da School of Hygiene and Public Health, da Johns Hopkins University, na área de concentração em Saúde Mental, e a uma viagem de treinamento a seis Centros de Saúde Mental Comunitária em algumas das mais prestigiosas escolas de medicina dos Estados Unidos (Yale, Harvard e Albert Einstein) e a alguns dos melhores Centros Comunitários de Saúde Mental urbanos e rurais, em estados com características culturais diversas. Ao regressar, o então Secretário da Saúde, Dr. Jair de Oliveira Soares, em novembro de 1972, fez o convite irrecusável para que eu dirigisse o Centro Médico Social São José do Murialdo, e que o fizesse já marcando nele a presença da Secretaria da Saúde do Rio Grande do Sul, realizando nele experiências inovadoras, com obra marcante do Governo do Estado do Rio Grande do Sul na contribuição do desenvolvimento do setor da saúde no estado e no país. Enquanto dirigi o Centro Médico Social São José do Murialdo, estiveram, sucessivamente, à frente do Governo do Estado, Synval Guazzelli e Jair Soares, e à frente da Secretaria de Saúde, Jair Soares e Germano Mostardeiro Bonow, sendo este também o Chefe da $1^{a}$ Delegacia Regional de Saúde na fase inicial do período em que estive na direção dessa organização. Esses nomes tiveram ousadia igual ou superior à nossa para oferecer o necessário e contínuo apoio político às referidas experiências. 
De novembro de 1972 a abril de 1974, um intenso trabalho de estudo de projetos internacionais e de avaliação, discussão e redação de um Projeto de Saúde Comunitária a ser implantado naquela área geográfica, foi realizado com a participação de todos os funcionários que exerciam as suas atividades no Centro Médico Social São José do Murialdo, com uma forte e muito presente contribuição das lideranças e de pessoas da comunidade. Com aval das autoridades referidas, de abril de 1974, quando o projeto terminou de ser redigido, até o momento em que, em 1982, passamos a chefia ao nosso sucessor, Dr. Flávio Kanter, cerca de 11 grupos de trabalho deram início à tarefa de tornar realidade o que determinavam os onze objetivos básicos do projeto. Com o objetivo geral de elevar os níveis de saúde da população da área geográfica de abrangência do Centro, com o atendimento integral (preventivo, curativo e reabilitador), continuado, personalizado e participativo da população daquela área, então com 28.850 habitantes, deu-se início à construção de um modelo de sistema de Saúde Comunitária, procurando atingir os objetivos acima referidos. Estes compreendiam que se reorganizasse a subdivisão da área total em cinco subáreas, servidas por cinco equipes inicialmente multiprofissionais, denominadas de equipes primárias. Também era necessário que se modificassem os serviços especializados no Centro de Saúde, para servirem de apoio e retaguarda aos locais de cuidados primários, e que houvesse um deslocamento gradativo das equipes primárias, concentradas de início no Centro de Saúde, para o coração de cada uma das subáreas, à medida que fossem construídos ou alugados locais adequados para brigar um Posto de Saúde dentro das mesmas.

Objetivos de desenvolvimento de assistência a prioridades, com técnicas de alta eficiência, e de boa prática assistencial, por meio do desenvolvimento do ensino e da pesquisa mais avançada para o que na época denominávamos Cuidados Primários de Saúde, para problemas prioritários (prevalentes, que preocupam a comunidade, importantes médico-socialmente e para os quais há tratamentos resolutivos), levaram também ao desenvolvimento de ensino e pesquisa consentâneos com as propostas do projeto. To- dos os programas de ensino existentes e propostos, a iniciar pelos estágios com alunos de graduação de escolas médicas de outras ciências, da saúde, sociais e humanas, e outras direta ou indiretamente envolvidas com a Saúde da Comunidade, passaram a ser integrados e conseqüentemente, multiprofissionais e interdisciplinares. O objetivo de uma organização escalonar dos serviços de saúde atingiu plenamente a busca de prover autocuidados e assistência domiciliar, na qual a unidade de atendimento era o domicílio do paciente ou os locais de encontro dos grupos sociais dentro das comunidades; a busca de Cuidados Primários, realizados por equipes primárias nos Postos de Saúde, hoje conhecidos como Unidades Básicas de Saúde também foi atingido. A busca de cuidados especializados básicos passou a ser realizada no Centro de Saúde existente, o qual concentrava também a chefia do sistema e suas coordenações, a de assistência, ensino, pesquisa e administração, bem como atividades de ensino e pesquisa. Estas exigiam espaços maiores para serem desenvolvidas, uma vez que abarcavam o ensino e a pesquisa no que lhes competia e que se faziam desde os domicílios até os Postos de Saúde quando não em outros locais de assistência, inclusive hospitalares, para onde eram transferidos alguns casos de alta complexidade, mas não deixando de formalizar a referência e a contra-referência dos clientes que passavam de um local para o outro, já não mais de uma forma anônima. Na prática, todos os onze objetivos previstos no Projeto foram atingidos de forma completa ou muito próxima do completo, tendo permanecido apenas como projeto escrito, o objetivo que propunha o desenvolvimento de um hospital comunitário o que só poderia ocorrer quando o sistema atingisse uma área de maior abrangência. Isso veio a ocorrer nos tempos atuais, estabelecendo as Unidades Básicas de Saúde como vanguardas dos Centros de Saúde e do sistema hospitalar como um projeto nacional, que é o marco referencial do nosso Sistema Único de Saúde, que está desenvolvendo-se no país há 20 anos. Um hospital comunitário não seria possível à época, sendo os casos mais complexos gradativamente transferidos para o sistema hospitalar existente, como até hoje ainda ocorre. 
A Unidade Sanitária Escola Murialdo antecipouse em cerca de quatro anos à Conferência de Alma-Ata e em cerca de quinze anos à criação do SUS, cujo desenvolvimento e aperfeiçoamento todos desejamos. Foi, pois, naquele local que se instalaram, a partir de abril de 1974, os primeiros Postos Avançados de Saúde, hoje conhecidos como as cinco primeiras Unidades Básicas de Saúde de nosso país. Cada um desses postos estava encarregado de um quinto da população da área - dividida em setores geográficos, mas com alguma afinidade sociocultural -, sempre vendo os indivíduos dentro do seu contexto familiar e social. Também naquele local foi, criada a primeira Residência em Medicina Geral Comunitária, oficialmente registrada na Comissão Nacional de Residência Médica do Ministério da Educação, no ano de 1976. Junto a essa, corria em paralelo, um curso de especialização multiprofissional para enfermeiros, assistentes sociais, psicólogos, farmacêuticos, bioquímicos, nutricionistas, fisioterapeutas, veterinários e administradores de empresas. A formação pós-graduada lato sensu multiprofissional, similar à residência, não era prevista àquela época, quando a instituição "residência" era somente médica, e o curso de especialização para não-médicos só encontrou seu amparo e formato legal e oficial dentro da Escola de Saúde Pública da Secretaria da Saúde do Estado do Rio Grande do Sul, como fato consumado.

A residência tomou à época o nome de Residência em Medicina Geral Comunitária, adequado àqueles tempos de luta pela democratização do país. Graças a ela e aos novos especialistas pós-graduados, surgiram a Sociedade Brasileira e as Sociedades Estaduais de Medicina Geral Comunitária. As diretorias da Sociedade Brasileira de Medicina Geral Comunitária e da Sociedade de Medicina de Família, que surgiram quando da reestruturação do SUS, criando os serviços necessários ao desenvolvimento da política nacional de saúde para todos, tiveram mais recentemente a feliz idéia de unirem-se, dando origem à Sociedade Brasileira de Medicina de Família e Comunidade. As sociedades estaduais, umas com o nome já atualizado de "associação" e outras conservando ainda o nome de "sociedade", levaram avante a idéia que se pensava já à época do desenvolvimento do projeto do sistema comunitário de saúde da Unidade Sanitária Murialdo, na qual os serviços básicos de saúde que se instalavam deveriam servir somente à assistência da população, mas também ao ensino, à pesquisa e à administração de serviços de saúde. O novo sistema exigia maior espaço para a formação de pessoal capacitado, um tipo novo de profissional ou, como se denominava à época, de recursos humanos básicos necessários para que a nação tivesse pessoas preparadas para a concretização do sonho de saúde para todos. Procurava suprir assim a necessidade de formar um tipo de profissional capaz de atuar nas Unidades Básicas de Saúde, nos Centros de Saúde da retaguarda e nos locais de maior complexidade e resolutividade que dariam acabamento à estruturação de uma rede hierárquica de atendimento da saúde da população. Foi assim dada e naturalmente aceita a idéia de associar o nome da Medicina Comunitária, com idéia maior de orientá-la ao objetivo de elevar o nível de saúde das famílias e das sociedades humanas, privilegiando nominalmente as duas primeiras formas de associação dos grupos humanos: a família e a comunidade.

A generosidade do reconhecimento de vocês em cumprimentar-me pessoalmente, por meio de telefonemas e pelo envio de flores, cartões, telegramas e lembranças outras é recebida por mim em nome de todos os que trabalharam nos anos épicos e criativos que foram aqueles que ocorreram entre 1972 e 1982, no Centro Médico Social São José do Murialdo. Contei com a colaboração de uma grande equipe, cujo trabalho de apoio e a liderança compartilhada nunca poderei deixar de reconhecer. Também nunca poderei retribuir o muito que recebi, em qualidade e em quantidade, das mais de uma centena de pessoas com as quais trabalhei naquela época. Eram profissionais de nível superior, médicos, enfermeiros, assistentes sociais, psicólogos, fisioterapeutas, dentistas, farmacêuticos, administradores, auxiliares de saúde, profissionais de saneamento e pessoal em treinamento, aí incluindo residentes em Medicina Geral Comunitária, pós-graduandos lato sensu, alunos de cursos de diversas graduações e de pós-graduação de várias universidades e escolas que lá estagiavam e muitos profissio- 
nais das mais diversas áreas, todos democraticamente aceitos, que lá se instalavam pioneiramente para aprender e para contribuir para a construção do campo da saúde que hoje chamamos de Medicina de Família e Comunidade.

Era uma verdadeira peregrinação para novos rumos em direção à construção de uma sistemática de trabalho dirigida à concretização de uma política de saúde para todos. Foi necessário abrir as portas do sistema para a população da área, bem como acolhê-la, não só como usuária, mas como participante desse sistema. $\mathrm{O}$ nosso modelo de sistema de saúde comunitária recebeu os membros da comunidade para ouvi-lo e treiná-los como trabalhadores da saúde, na condição de voluntários. Estes eram escolhidos pelos grupos populacionais da comunidade dentre as pessoas por ela conhecidas e respeitadas e que se dispunham dar parte de seu tempo de lazer ou de descanso para o desempenho de tarefas de saúde, fossem elas no campo físico, psicológico ou social. Para o grupo dos que procuravam participar dos cuidados mais diretamente ligados à saúde e para os que trabalhavam em atividades de agregação social para busca de solução de problemas coletivos das comunidades envolvidas, como os problemas de saneamento básico, era oferecido um curso de treinamento de voluntários de saúde, que corria regularmente todos os anos, por vários meses, em horários extraordinários, para poder acolher pessoas da população com trabalho regular em outros locais. Destaco a criatividade da enfermeira Dinalva Scaravaglione, não deixando também de reconhecer o esforço da enfermeira Noely Ângelo e do chefe da Oficina de Saneamento Paulino Vaz no desenvolvimento desse tipo de treinamento. Estas atividades de ensino ficaram denominadas como treinamento de voluntários da saúde e treinamento de auxiliares de saúde, para cuja consolidação os colegas acima citados foram extremamente criativos e competentes. Para as pessoas que vinham dos campos já tradicionais da área da saúde, bem como para os que vinham das áreas das Ciências Sociais, da Educação e da Cultura, e que desejavam ter conhecimento do que se trabalhava em um sistema de saúde comunitária, era programada uma forma de treinamento em serviço ou de atividade participativa no desenvolvimento do modelo de sistema, em um estágio similar ou conjunto ao já referido estágio integrado, com algumas atividades próprias, denominado por nossa coordenação de ensino, de estágio de familiarização.

Assim, foi se consolidando o Sistema de Saúde Comunitária da Sanitária Murialdo, sempre pensando na abertura do campo da saúde, primeiramente à população da sua área de abrangência e, posteriormente, para todos que viessem em busca de uma informação ou de uma formação convencional dentro do sistema inovador que se desenvolvia, enfim, para todos que se dessem guarida à idéia de que todo o sistema de saúde deveria ter como objeto fundamental a elevação do nível de saúde da população. É certo que uma organização pioneira na busca de uma nova forma de prestação de serviços de saúde e de administração dos mesmos teria que se estruturar como um local de ensino ou treinamento de pessoal e de pesquisa, irmã natural do ensino. Tínhamos consciência de que a construção e a administração de uma nova forma de assistência exigiriam um ensino e uma pesquisa extremamente fortes, partes integrantes do serviço e só passíveis de serem assimilados se realizados dentro de uma experiência que aliasse, ao ensino "teórico", a prática daquilo que se projetava transmitir. A busca da organização de um sistema de uma formação de pessoal que projetasse e proporcionasse às populações uma saúde para todos, viessem esses profissionais das Ciências Humanas, das Ciências Sociais e da Administração era bem-vinda.

Um número incontável de pessoas veio ajudar na construção do Sistema de Saúde Comunitária da Unidade Sanitária Murialdo. Certamente, nós "tivemos muitos colegas, irmãos, amigos, que tantos não podemos mais contar". Porém, representando a todos, lembro Isaac Lewin, que prematuramente perdemos, Sérgio Pacheco Ruschel, Patrícia Bradley e Lynda Hirata Ellingson (estas, Voluntárias do Peace Corps, dos Estados Unidos), Jorge Carbajal (do Instituto de Antropologia do Peru, assessor da OPAS), que nos ajudaram na construção e na realização do Projeto e o já então Médico de Família Sênior, Carlos Grossman, este já tam- 
bém agraciado pela Sociedade Brasileira de Medicina de Família e Comunidade, que, com outros nomes já incidentalmente citados neste longo agradecimento, brilhantemente representam os "incontáveis" trabalhadores da saúde, profissionais ou voluntários que desenvolviam atividades na época no Centro Médico Social São José do Murialdo Unidade Sanitária Escola Murialdo. Fundamental para o desenvolvimento dos Cuidados Primários da Saúde, hoje Atenção Básica à Saúde, foi a consecução do objetivo que previa um Programa de Residência em Saúde Comunitária; era a introdução do Médico de Família e Comunidade na história da medicina do Brasil. Destaco a Cooperativa Tritícola de Ijuí (COTRIJUI) e o Serviço Social da Indústria (SESI) que, cada um por dois anos, ao longo de quatro anos, repassaram à Secretaria de Saúde, um montante necessário para o pagamento das bolsas dos residentes, Carlos Grossman negociou com a Presidência da COTRIJUí, e eu mesmo, com o então diretor do SESI, Dr. Luiz Octavio Vieira aqueles financiamentos que, naquele momento, não poderiam ser providos pelo Estado.

Casualmente, eu aniversario no mês de maio, e muitos de vocês cumprimentaram-me pelos dois motivos. Não tenho dúvidas de que entre o aniversário, que marca para nós uma passagem na vida, e o prêmio, que marca outro tipo de passagem - a de nossas obras -, fico mais gratificado pela segunda, pois me diz que o realizado não o foi em vão. Devo dizer-lhes que a Medicina de Família e Comunidade foi uma atividade que muito me completou na minha forma de ser profissional, com obrigações e deveres de dirigir e de liderar os colegas de forma participativa. Também por ter sido uma atividade que pude levar ao mais completo acabamento possível à época, desde o projeto à realização do mesmo, quando, no início, era quase impossível vislumbrar que, ao fim de 10 anos, o Sistema de Saúde Comunitária estaria teórica e praticamente acabado. Um projeto experimental, unindo assistência, ensino, pesquisa e administração, de cuja autoria fui coordenador e também sujeito, partindo do atendimento da demanda para o atendimento da necessidade, dando assistência à saúde física, mental e social de forma integral (preventiva, curativa e reabilitadora), continuada, personalizada e participativa, foi o cumprimento de um dever a que eu me obrigara para com a minha profissão médica, como eu a entendo, ou seja, uma ciência do humano, e para com o meu país, que eu o desejo saudável física, psíquica e socialmente. É certo que temia não poder atingir a meta de instalar uma forma de assistência à saúde, unida a um ensino, a uma pesquisa e a uma administração afins e conseqüentes ao objetivo maior, que é o de proporcionar, na medida do possível e do impossível, o maior grau de saúde física, mental e social às populações da área de abrangência da Unidade Sanitária Murialdo, como um modelo experimental para o nosso município, para o nosso estado e para o nosso país. Mas é certo, também, que cumprimos com esse objetivo.

Essa foi, talvez, a tarefa de maior relevância que me coube durante toda a minha vida médica em serviços públicos, dada a condição de indigência em que se encontrava a organização dos serviços de saúde em nosso país à época.

Como psiquiatria, cumpri outras, tais como a de repensar a psiquiatria e a medicina como uma ciência da saúde do homem, e não do combate à doença mental, tal como se pensava nos meus primeiros contatos com as minhas amadas profissão (medicina) e especialidade (psiquiatria). Mas, naquele momento de minha vida, o que importa foi ter participado do desenvolvimento da idéia de que minha ciência deveria pensar que a saúde, como condição de bem-estar físico, mental e social e não apenas como ausência de doenças, e que este deve ser um objetivo de todos os serviços de saúde e de todos os que neles trabalham. Também esta é a idéia que está mais de acordo com o meu sonho conscientemente quixotesco, não tão impossível, de que, um dia, chegaremos a trabalhar com a saúde física, mental e social de todos e não mais com as doenças de poucos. No meu sonho impossível as doenças deverão ser, no futuro, extintas. Eu tenho um sonho e espero que os médicos do futuro estejam trabalhando na fortificação dos aspectos saudáveis do homem, na sua cada vez maior humanização.

Muito comovido e muito agradecido a vocês todos, 
fica o sonhador que ainda sonha e que ainda está longe de concretizar ou de ver concretizados todos os seus sonhos, mas que tem consciência de que deu sua possível e bem disponível contribuição para que o sonho de saúde para todos desse um passo para frente. Outros mais virão para alcançarmos o triunfo do humano e da humanidade sobre o inumano, da civilização sobre a barbárie e da saúde sobre a doença.

Muito, mas muito mesmo, obrigado.

Ellis Alindo D’Arrigo Busnello. 